\title{
Sustained partial remission of a metastatic NEN using off-label immunotherapy with pembrolizumab
}

\author{
Anna Kathrin Stüven ${ }^{1}$ and Bertram Wiedenmann ${ }^{1}$ \\ 1 Department of Hepatology and Gastroenterology, Campus Virchow-Klinikum and Campus Charité Mitte, Charité- \\ Universitätsmedizin Berlin, Berlin, Germany \\ Correspondence to: Anna Kathrin Stüven, email: anna-kathrin.stueven@charite.de \\ Keywords: NET/NEC G2/3; pembrolizumab; immunotherapy; PD-L1 \\ Received: September 26, $2018 \quad$ Accepted: March 23, $2019 \quad$ Published: May 14, 2019 \\ Copyright: Stüven et al. This is an open-access article distributed under the terms of the Creative Commons Attribution License 3.0 (CC BY \\ 3.0), which permits unrestricted use, distribution, and reproduction in any medium, provided the original author and source are credited.
}

\section{ABSTRACT}

Neuroendocrine neoplasms (NEN) are a heterogeneous group of tumors, which can be histologically separated by primary location, proliferation rate and differentiation of tumor cells.

The therapeutic options and outcome depend on grading, staging and resectability of the tumor. Established treatment options of neuroendocrine tumors (NET) and carcinomas (NEC) are based especially on surgery, tumor specific medical treatments, peptide guided radioreceptor therapy (PRRT) and locoregional therapies.

We report about a patient diagnosed with a pancreatic, non-functional NET/ NEC G2/3 with a proliferation rate of $20 \%$ at initial immunohistochemical diagnosis. During the course of the disease, the proliferation rate increased up to more than $50 \%$ over a period of 5 years. Due to loss of response to established therapies (i.e. systemic chemotherapy, targeted therapy and brachytherapy), an off-label immunotherapy with the PD-1 antibody pembrolizumab was initiated based on a 30\% PD-L1 expression in tumor cells.

This report is the first demonstrating a partial remission of a pancreatic NEN using pembrolizumab monotherapy with a hepatic tumor volume reduction of at least $66 \%$, combined with an improvement of the Karnofsky score rising from $60 \%$ to $100 \%$. This case offers insight into the potential role of immunotherapy in a subgroup of neuroendocrine neoplasms.

\section{INTRODUCTION}

Neuroendocrine neoplasms (NEN) are heterogeneous tumors, which can be differentiated between the broad spectrum of low-proliferating and welldifferentiated neuroendocrine tumors (NETs) to highlyproliferative and poorly differentiated, neuroendocrine carcinomas (NECs).

The current World Health Organization classification of gastrointestinal and pancreatic neuroendocrine neoplasms (GEP-NEN) uses the Ki 67 proliferation index to grade NETs as G1, G2, or NEN G3 with a high degree of proliferation $[1,2]$. The group of NEN G3 is subdivided into NET and NEC, both characterized by significant differences in cell morphology and differentiation, proliferation index (Ki 67), progression-free survival (PFS) after chemotherapy, and outcome [3, 4].
Current guidelines for the treatment - as in the presented case - of a non-functional, metastatic pancreatic NET/NEC G2/3 recommend an anti-proliferative therapy with a somatostatin analogue [5] or systemic therapies including streptozotocin, temozolomide, everolimus or sunitinib [5].

Once NEN progress into an accelerated rate of proliferation and become a NEC, platinum-based chemotherapeutic regimens represent the treatment of choice $[5,6]$. Given the almost obligatory, initial tumor response, therapeutic resistance also develops consistently. Therefore, dedifferentiated tumors/carcinomas have a poor prognosis and metastasize early to distant sites $[6,7]$.

In consequence, new alternative therapies are needed. Hence, immunotherapy has been explored as a potential and relevant therapeutic option for the treatment of NEC/T G2/G3. 
For immunotherapy, several receptor-ligand systems (RLS) influence immune responses. A well-established example of these RLS is programmed death 1 receptor (PD-1), a cell-surface molecule promoting self-tolerance by suppressing T-cell inflammatory activity. Immune checkpoint inhibitors offer the possibility to enhance the immune responses by intensifying the regulatory role of PD-1 [8-11]. One of the checkpoint inhibitors for PD-1 is the monoclonal antibody pembrolizumab, blocking the binding site of the receptor ligand PD-L1. The ligand is partially expressed by neuroendocrine tumors, especially in patients with metastatic GEP-NEC. PD-L1 expression of the tumor cells appears to be significantly associated with high-grade G2/G3 NEN [12] and is also significantly associated with a longer PFS in first-line treatment [8].

In addition, as recently reported, patients with Merkel-cell carcinoma expressing PD-L1 within the tumor tissue benefit from immunotherapy $[13,14]$. It has been shown that, unlike chemotherapy, treatment with antiPD-1 and anti-PD-L1 leads to a durable response in these patients [15]. As a result of this outcome, in September 2017 the European Commission approved avelumab, a PD-L1 inhibitor, to treat metastatic Merkel-cell carcinoma [16].

Based on the expression of PD-L1 and a sometimesoccurring high mutation rate, NEN G2/G3 are potential candidates for immunotherapy with for example pembrolizumab as checkpoint inhibitor [17-19].

This is the first case reporting a successful immunotherapeutic approach using pembrolizumab alone in a metastatic pancreatic neuroendocrine tumor.

\section{CASE REPORT}

In this case study, a 55-year-old male patient was diagnosed in August 2012 with a non-functional pancreatic NET G2/G3 (according to the WHO 2010 classification) and synchronous liver metastasis with a hepatic tumor load of already $70 \%$. In addition to the hepatic dissemination, metastasis also affected additional distant sites such as the spleen, kidneys, adrenals, peritoneum and lymph nodes. A table of the entire course of disease is provided in Figure 1 .

As an indication of tumor wasting, tumor dissemination led to a weight loss of $10 \mathrm{~kg}$ over 8 months. Figure 2.

Immunohistochemistry of a liver biopsy showed co-expression of synaptophysin, CK18, CK20, CD56 but negativity for Chromogranin A, CK7 and CA19.9. At initial diagnosis in 2012, Ki 67 was $20 \%$, whereas in 2016 it had increased to $>50 \%$ and in 2017 was reduced to $35 \%$. Membranous PD-L1 expression was found in 30\% of the tumor cells in the liver biopsy, both in 2016 and 2017. Figure 3.

In vivo somatostatin receptor imaging by Ga68DOTATOC-PET-CT and tectreotide-scintigraphy showed a heterogenous somatostatin receptor expression with positivity for the primary tumor, but negativity for the liver metastases. Therefore, PRRT was excluded as a therapeutic option.

Due to the widespread dissemination of the tumor, curative surgery was not feasible. Consequently, firstline chemotherapy using FOLFOX was started in 2012 externally. Due to tumor progression, a second-line combination therapy using temozolomide and capecitabine was initiated.

Although the combination of temozolomide and capecitabine led to a stable disease for more than three years, eventually tumor resistance developed in 2016.

In October 2016, consecutive locoregional brachytherapy using an after-loading technique [20, 21] showed also fast progression of the hepatic metastases. Similarly, everolimus, an mTOR-inhibitor, was experimentally initiated despite a high $\mathrm{Ki} 67>50 \%$ [22, 23]. Everolimus had to be discontinued after three months based on pneumonitis as adverse effect. Another targeted drug, sunitinib, was excluded due to the expected lack of response to treatment and side effects such as arterial hypertension and bleeding based on the existing portal hypertension [24, 25].

Following all failed treatments, an additional large (78 $\mathrm{mm}$ in diameter) metastasis of the left kidney led to macrohematuria. The renal metastasis was treated with cyber knife and palliative local radiation, which led to a cessation of hematuria. 4th line systemic chemotherapy with FOLFIRI was initiated. Following also progression with FOLFIRI in June 2017, pembrolizumab, a highly selective, humanized monoclonal IgG4-kappa isotype antibody against PD-1 was started. Treatment began with $150 \mathrm{mg}$ i.v. ( $2 \mathrm{mg} / \mathrm{kg}$ body weight) every 21 days and was deescalated to $100 \mathrm{mg}$ every cycle due to pancytopenia [26]. For the following cycles, therapy with $140 \mathrm{mg}$ was used without further side effects and recovery of hematopoiesis.

Until April 2018, monotherapy using PD-1-blocker led to a sustained partial remission with a hepatic tumor size reduction of at least $66 \%$ and a Karnofsky score of $100 \%$. Figure 4.

Already three applications over a period of three months led to a partial remission with distinct regression of the hepatic, kidney and adrenal metastasis as shown by CT-imaging (Figure 5, 6). In addition, the general health condition including physical activity and health related quality of life (QoL) of the patient improved. Applying pembrolizumab, the patient gained $5 \mathrm{~kg}$ weight, stopped analgesics such as metamizole and tramadol, and resumed full time work again. Current physical examination after the thirteenth application of pembrolizumab over 9 months showed, that the liver gained normal size again, starting at initial diagnosis at mean corpuscular length of $190 \mathrm{~mm}$ in $08 / 2012$ to $110 \mathrm{~mm}$ in $06 / 2017$. In addition, CT-imaging revealed an impressive regression of the hepatic metastasis 


\begin{tabular}{|c|c|c|c|}
\hline \multicolumn{4}{|c|}{ Course of disease } \\
\hline & & \multicolumn{2}{|c|}{$\begin{array}{l}\text { - Non-functional pancreatic NET G2/G3, synchronous liver metastasis } \\
\text { - Hepatic tumor load of } 70 \% \\
\text { - Additional distant metastases (lymph nodes, peritoneum, adrenals, kidney and spleen) } \\
\text { - Portal hypertension with gastric fundal varices and splenomegaly } \\
\text { - Co-expression of synaptophysin, CK18, CD56, CK20 and negativity for CK7 and CA19.9 } \\
\text { - No expression of Chromogranin A } \\
\text { - Ki } 67 \text { in hepatic biopsy initially (2012) } 20 \% \\
\text { - Membranous PD-L1 expression } 30 \%\end{array}$} \\
\hline & Year & Therapy & Staging \\
\hline 2012 & $08 / 2012$ & & $\begin{array}{l}\text { Pancreatic NET G2/3; cT3, N1, M1 (lymph nodes, peritoneum and } \\
\text { spleen) } \\
\text { Karnofsky score of } 90 \%\end{array}$ \\
\hline \multirow[t]{3}{*}{2013} & $\begin{array}{l}08 / 2012- \\
06 / 2013\end{array}$ & \#18 FOLFOX & \\
\hline & $06 / 2013$ & & $\begin{array}{l}\text { Staging CT: Progressive disease with spleen metastasis, hepatic } \\
\text { progressive disease }\end{array}$ \\
\hline & $\begin{array}{l}06 / 2013- \\
01 / 2017\end{array}$ & $\begin{array}{l}\text { Temozolomide/ } \\
\text { Capecitabine (TEMCAP) }\end{array}$ & \\
\hline \multirow[t]{2}{*}{2014} & $03 / 2014$ & & $\begin{array}{l}\text { Staging: SRS, no tracer-uptake, cT3, N1, M1 (lymph nodes, } \\
\text { peritoneum and spleen) }\end{array}$ \\
\hline & $06-09 / 2014$ & & $\begin{array}{l}\text { Regression of the primary and the hepatic metastasis, partly } \\
\text { progressive disease }\end{array}$ \\
\hline 2015 & $10 / 2015$ & & Stable disease \\
\hline \multirow[t]{5}{*}{2016} & 09/2016 & & $\begin{array}{l}\text { Staging FDG PET: inhomogeneous hepatic tracer uptake with } \\
\text { hepatic progressive disease }\end{array}$ \\
\hline & $09 / 2016$ & & Staging Ga68 DOTATOC-PET-CT: hepatic progressive disease \\
\hline & $10 / 2016$ & & $\begin{array}{l}\text { Hepatic progressive disease, primary of constant size } \\
\text { re-biopsy of the liver: PD-L1 } 30 \% \text { membranous } \\
\text { Ki67: >50\% }\end{array}$ \\
\hline & $10 / 2016$ & & Brachytherapy \\
\hline & $12 / 2016$ & & Hepatic progressive disease and new hepatic metastases \\
\hline \multirow[t]{9}{*}{2017} & $01-04 / 2017$ & Everolimus & \\
\hline & $03 / 2017$ & & Staging CT: Everolimus induced pneumonitis \\
\hline & $04 / 2017$ & & Progressive disease \\
\hline & $04 / 2017$ & \#1 FOLFIRI & \\
\hline & $05 / 2017$ & $\begin{array}{l}\text { \#2 FOLFIRI } \\
\left.\text { leukopenia }{ }^{\circ} \mathrm{II}\right)\end{array}$ & \\
\hline & $05 / 2017$ & $\begin{array}{l}\# 3 \text { FOLFIRI } \\
\left.\text { leukopenia }{ }^{\circ} I I\right)\end{array}$ & \\
\hline & $06 / 2017$ & & Hematuria and edema; new adrenal and kidney metastases \\
\hline & $06 / 2017$ & & $\begin{array}{l}\text { CT Staging: hepatic progressive disease; Ki67 } 35 \% \text {; Initial diagnosis } \\
\text { of kidney metastases }\end{array}$ \\
\hline & $06 / 2017$ & & Re-biopsy of the liver: PD-L1 $30 \%$ membranous \\
\hline
\end{tabular}

\section{Figure 1: Course of disease.}


whereby in 11/2017 some lesions disappeared and other lesions as in segment $2 / 3$ regressed from $60 \times 40 \mathrm{~mm}$ in $09 / 2017$ to $20 \times 16 \mathrm{~mm}$ in 04/2018. Figure 5, 6 .

Apart from a pembrolizumab induced pneumonitis of a low degree of severity with no clinical symptoms, we could not observe any other potential side effects known for pembrolizumab therapy such as fatigue, skin rush, diarrhea or allergic reaction during application [26].

Following 13 applications of pembrolizumab, therapy had to be paused due to pneumonitis and continued following a successful treatment with steroids. Until now, a persistent partial remission is observed.

\section{DISCUSSION}

To the best of our knowledge, the presented case represents the first report of successful treatment of a far advanced, metastatic pancreatic NET/NEC G2/G3 following partial, sustained remission over 13 months by now using a PD-1-blocker.
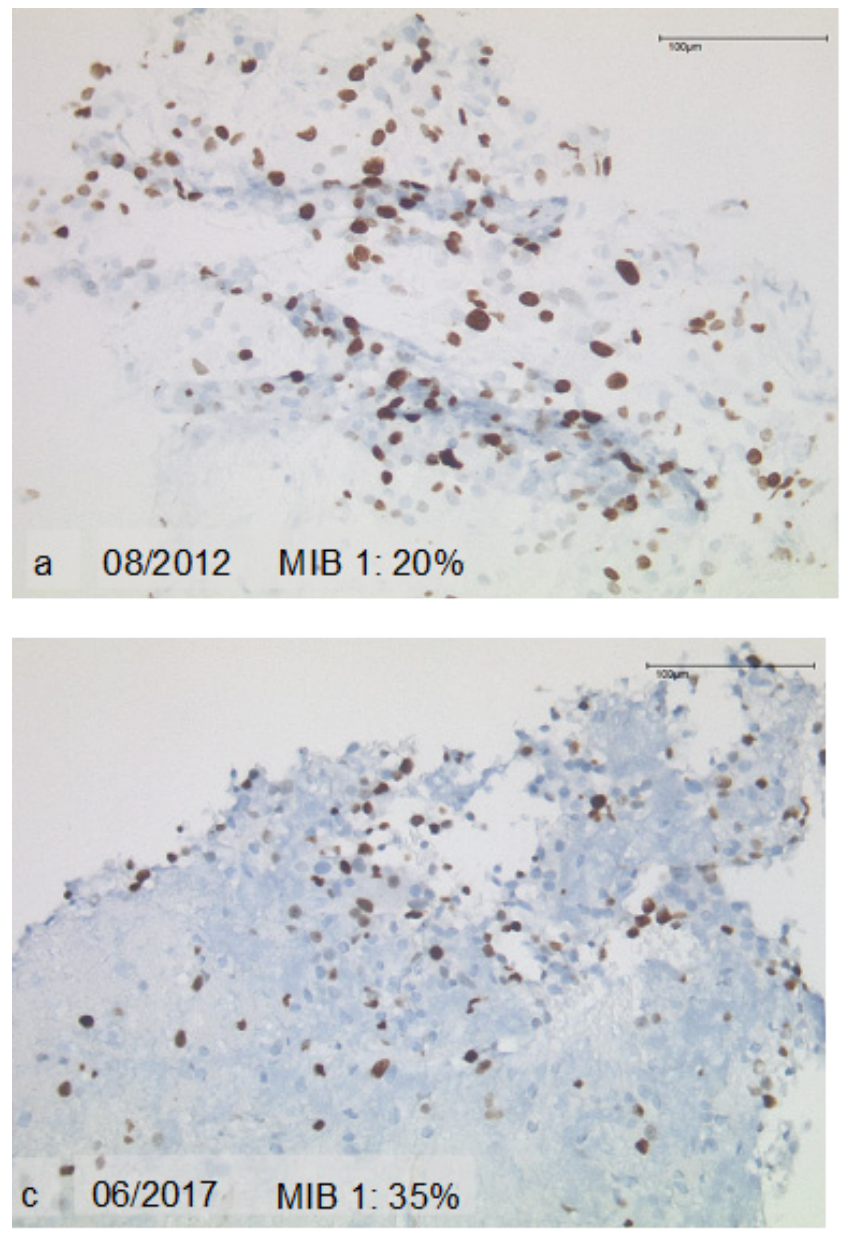

Until now, off-label treatment with pembrolizumab for pancreatic neuroendocrine tumors/carcinomas has not been successfully used. So far, only a case report on successful immunotherapy of a gastric NET/C exists (36). However, the presented case demonstrates quite well that off-label use may be considered in some cases of pancreatic NET/C once no other therapeutic option exists and PD-L1 expression in tumor cells is observed [27-29].

The objective response of our patient is best explained by the high PD-L1-positivity, despite the high proliferation rate of $\mathrm{Ki} 67$ of $35-50 \%$ [18]. In most reported cases so far, patients with high PD-L1 expression benefit from immunotherapy and often have a superior overall-response rate [30, 31]. Figure 7.

In consequence, PD-L1 expression appears to be a potential predictive marker. However, the validity is restricted by a broad diversity of assays with no standard antibody, and no standardized cut-off score for PD-L1 expression level, dividing tumor tissues into high- and low levels.

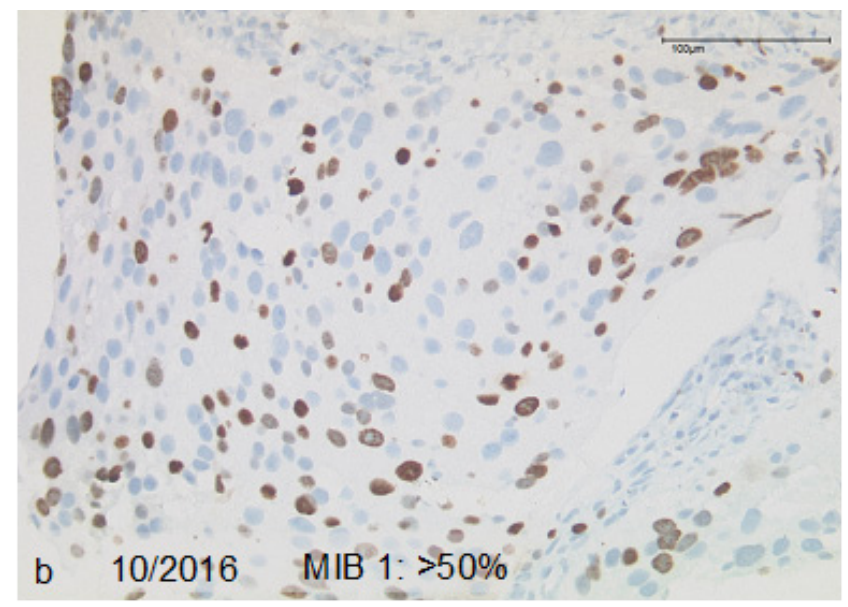

Figure 2: Proliferation during the course of disease. a. MIB 1 of $20 \%$ at initial diagnosis. b. MIB 1 of $50 \%$ after 4 years of treatment. c. MIB 1 of $35 \%$ at the beginning of treatment with pembrolizumab. 
In addition, latest research concerning modified immune response by exemplarily using vaccination, dendritic-cell-based therapy or indoleamine-2, 3-dioxygenase (IDO) inhibition in combination with PD-L1 related immunosuppressive mechanisms has to be considered in a future therapeutic prediction scenario [32-35]. For example, IDO inhibition combined with pembrolizumab therapy might enhance the odds ratio by improving T-cell activation in tumor cells [36]. Therefore, additional predictive biomarkers are necessary to evaluate patients that may benefit from immunotherapy. Aside from using PD-1 blockers, there is an educated guess, that the burden of neoantigens correlates with effectiveness of immunotherapies in NEN, like it is shown in other tumor entities [37]. It is well known, that GEP-NEC show a high chromosomal instability and microsatellite instability (MSI) rarely [38-41]. The presence of MSI seems to be associated with a better outcome, whereas the occurrence

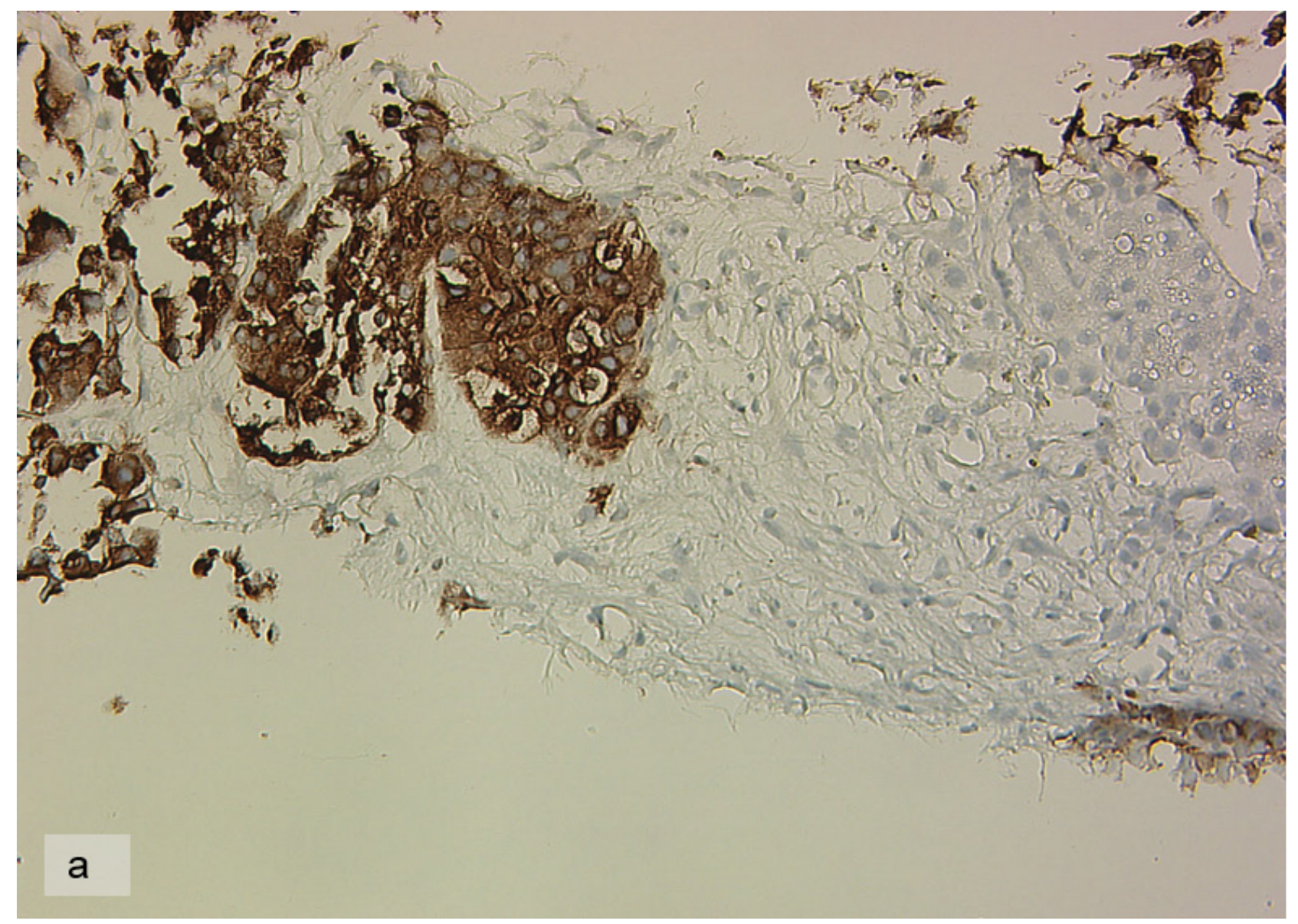

Figure 3: Synaptophysin-expression of the tumor cells.

a

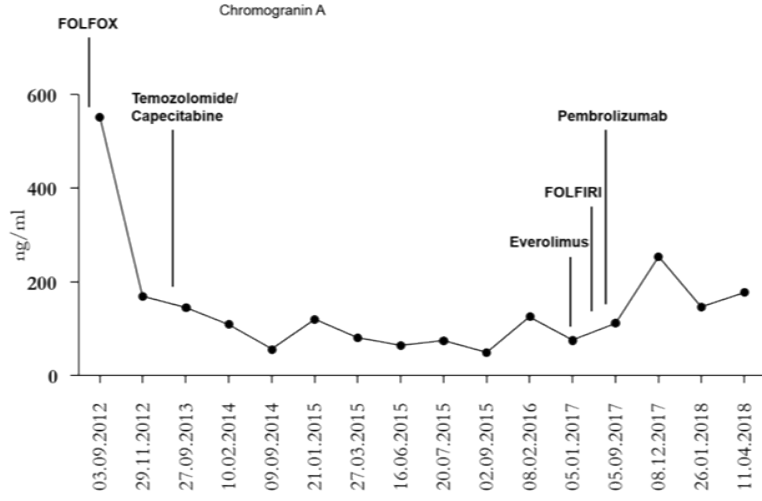

b

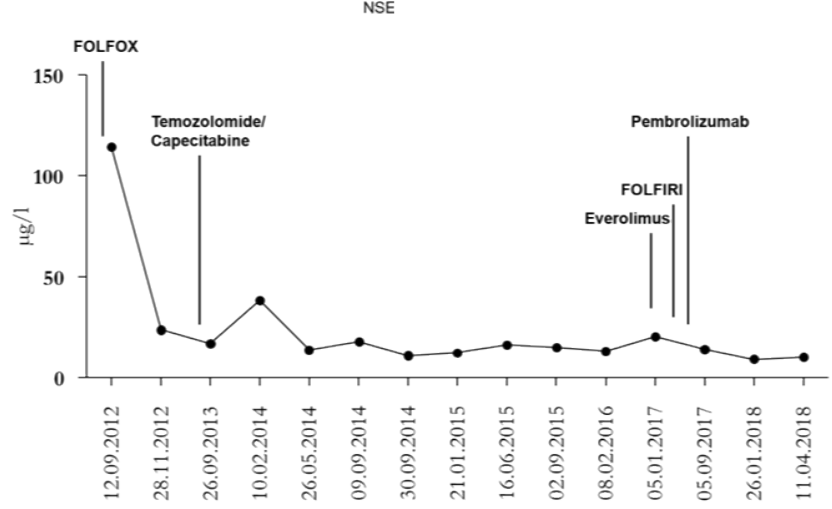

Figure 4: Tumor markers Chromogranin A and NSE during the different treatments. NSE seems to correlate with the effectiveness of the therapy, while Chromogranin A is not able to predict cytoreduction. 
of mismatch repair antigens seems to be dependent on the microsatellite stable - NECs [18].
Furthermore, since we have already successfully treated another patient with pembrolizumab and
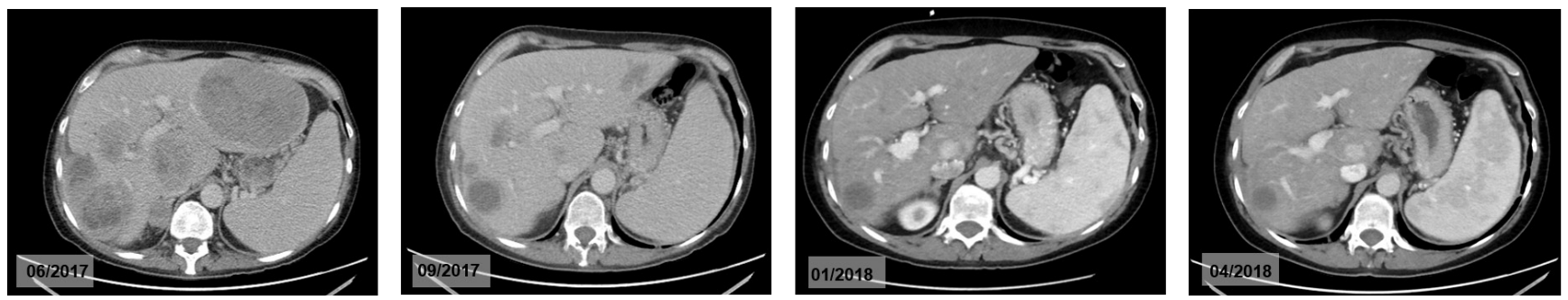

Figure 5: Metastases of the liver during the checkpoint-inhibition with pembrolizumab. It presents the hepatic tumor reduction of $66 \%$ from $06 / 2017$ to $04 / 2018$.
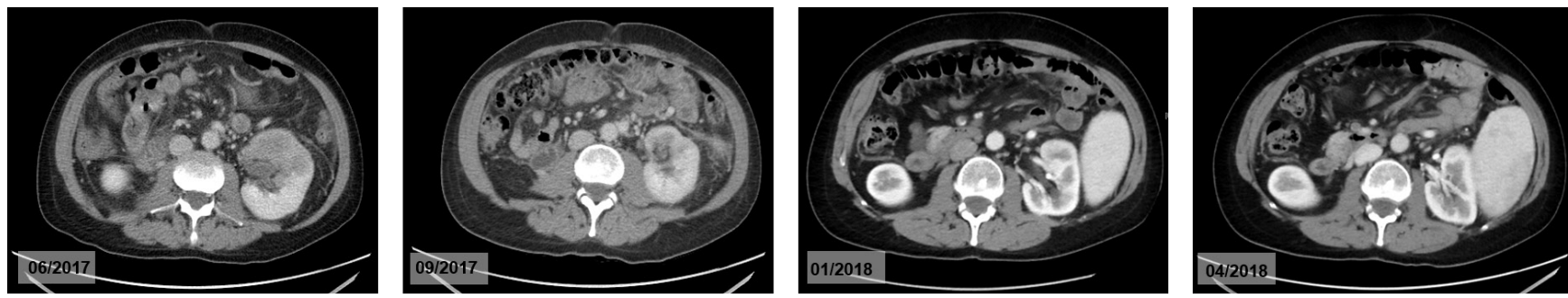

Figure 6: Renal metastases in CT-staging before and after the therapy with pembrolizumab. It reveals the distinct reduction of tumor size during a 10 -month treatment.

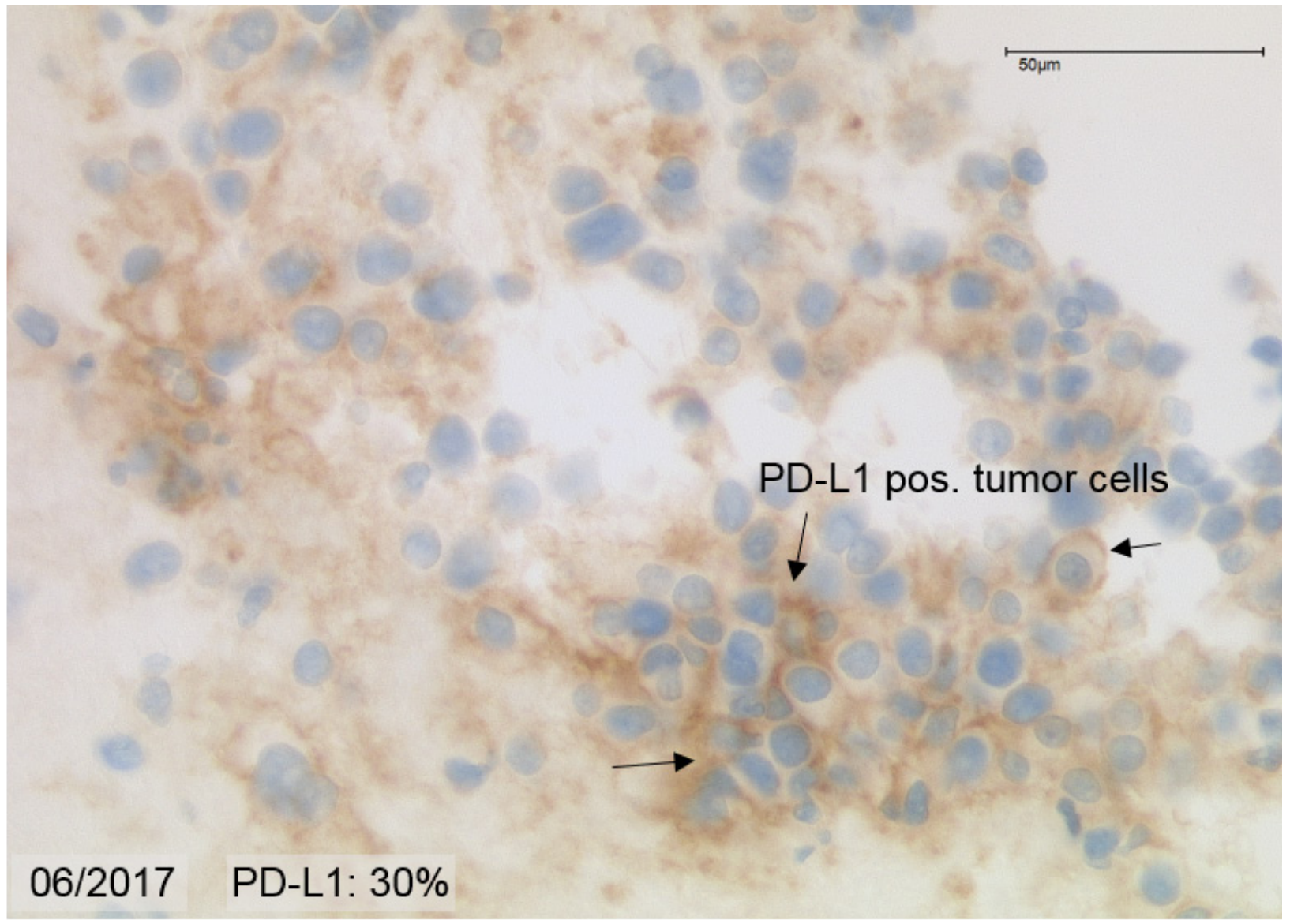

Figure 7: PD-L1 Immunoreactivity in 06/2017. In 30\% of the tumor cells are immunoreactive. 
ipilimumab long term [42], based on a high mutational burden, it is tempting to speculate that long-term remission may also be observed in the presented patient with elevated PD-L1 expression as a predictive marker for therapeutic response.

This would also in turn imply that control of typical side effects such as persistent pneumonitis has to be considered interfering with constant treatment. However, based on the observed durable response in Merkel-cell carcinoma, the experience at our site and the current data, it is reasonable to argue for a durable remission in the presented case $[43,44]$. In case of future progressive disease, the combination of pembrolizumab with ipilimumab could be a therapeutic option for our patient. The combined therapy appears to lead to a longer PFS and a higher response rate than a monotherapy with ipilimumab. However, in comparison with a PD1 -antibody monotherapy, the occurrence of treatmentrelated adverse events of the combined therapy have to be considered very carefully and balanced against the therapeutic benefit [45].

Regarding patients with DNA-repair-deficiency, pembrolizumab also offers new treatment options in a neoadjuvant setting [46]. Increasing the extent of genetic instability by combined radiotherapy (RT) leading to an increased immunotherapeutic response has been described for rectal adenocarcinoma, melanoma, breast cancer and also NSCLC $[47,48]$. It was also shown that RT is able to re-program the microenvironment of the tumor and is responsible for immune-mediated tumor rejection. For example, RT can upregulate the expression of PDL1 $[49,50]$. These therapeutic opportunities seem to be noteworthy for patients with neuroendocrine tumors as well.

Another interesting point for further work is to identify and evaluate the potential influences of pretreatment versus first-line treatment with pembrolizumab on the course of disease in neuroendocrine tumors. As shown for treatment with antibiotics, pretreatment might influence the composition of intestinal microbiota and therefore the outcome of patients treated with pembrolizumab [51, 52]. Current research shows that the gut microbiota seem to determine the effectiveness of anticancer immunotherapies and also provides new prognostic markers as a potential target for immunotherapy [53].

Further work might appreciate the transformation in proliferation during the period of treatment. As also observed in another case report of immunotherapy in neuroendocrine tumors, the proliferation index decreased during therapy [42]. This could be a working point for future evaluation of the tumor grading, leading to therapeutic adaptation or potential new treatment options.

In summary, the presented case report provides first evidence that immunotherapy may not only be effective in Merkel-cell and small cell carcinoma but also in the subset of NEN like pancreatic neuroendocrine tumors. Though the outcome cannot be generalized for any pancreatic NEN, in the presented case report monotherapy of pembrolizumab is able to reduce the tumor load and also leads to a dramatic gain of a health-related QoL. In this explicit case, a multimodal combination of systemic chemotherapy, local radiotherapy, and mTOR-inhibition seemed to be less effective for persistent remission and tumor-size reduction than the checkpoint inhibition of pembrolizumab.

Therefore, the clinical course of the metastatic pancreatic neuroendocrine tumor $\mathrm{G} 2 / \mathrm{G} 3$ with distinct partial remission in combination with an impressive gain of QoL and pain relief should arouse interest for the therapeutic capability of immunotherapy in neuroendocrine tumors.

\section{CONCLUSIONS}

Metastatic pancreatic neuroendocrine tumors G2/3 can be successfully treated - in selected cases - with pembrolizumab, a highly selective PD-1-antibody, leading to a partial remission and thereby reducing the metastatic liver tumor load by at least $66 \%$ over at least one year. Furthermore, a high health-related quality of life and pain relief could be accomplished within several weeks after the initiation of immunotherapy.

So far, the molecular mechanisms are not entirely understood and explored; PD1-checkpoint inhibition appears to be a treatment option in a subgroup of metastatic neuroendocrine neoplasia.

Multimodal treatments including immunotherapy can lead to a long survival of patients with metastatic NEN whereby sustained partial remission can be observed over a period of 6 years. Therefore, we suggest the use of immunotherapy as a therapeutic option for a subgroup of NEN-patients with distant metastases refractory to conventional treatments.

\section{CONFLICTS OF INTEREST}

The authors declare no potential conflicts of interest.

\section{FUNDING}

The authors received no specific funding for this work.

\section{REFERENCES}

1. Kloppel G. Neuroendocrine Neoplasms: Dichotomy, Origin and Classifications. Visc Med. 2017; 33:324-30.

https://doi.org/10.1159/000481390.

2. Scoazec JY, Couvelard A. [Classification of pancreatic neuroendocrine tumours: Changes made in the 2017 
WHO classification of tumours of endocrine organs and perspectives for the future]. [Article in French]. Ann Pathol. 2017; 37:444-56.

https://doi.org/10.1016/j.annpat.2017.10.003.

3. Heetfeld M, Chougnet CN, Olsen IH, Rinke A, Borbath I, Crespo G, Barriuso J, Pavel M, O'Toole D, Walter T. Characteristics and treatment of patients with G3 gastroenteropancreatic neuroendocrine neoplasms. Endocr Relat Cancer. 2015; 22:657-64.

https://doi.org/10.1530/erc-15-0119.

4. Kloppel G, La Rosa S. Ki67 labeling index: assessment and prognostic role in gastroenteropancreatic neuroendocrine neoplasms. Virchows Arch. 2018; 472:341-349.

https://doi.org/10.1007/s00428-017-2258-0.

5. Falconi M, Eriksson B, Kaltsas G, Bartsch DK, Capdevila J, Caplin M, Kos-Kudla B, Kwekkeboom D, Rindi G, Kloppel G, Reed N, Kianmanesh R, Jensen RT. ENETS Consensus Guidelines Update for the Management of Patients with Functional Pancreatic Neuroendocrine Tumors and Non-Functional Pancreatic Neuroendocrine Tumors. Neuroendocrinology. 2016; 103:153-71.

https://doi.org/10.1159/000443171.

6. Garcia-Carbonero R, Sorbye H, Baudin E, Raymond E, Wiedenmann B, Niederle B, Sedlackova E, Toumpanakis C, Anlauf M, Cwikla JB, Caplin M, O'Toole D, Perren A. ENETS Consensus Guidelines for High-Grade Gastroenteropancreatic Neuroendocrine Tumors and Neuroendocrine Carcinomas. Neuroendocrinology. 2016; 103:186-94. https://doi.org/10.1159/000443172.

7. Ma X, Zhao W, Zhuang C, Wang X, Tu L, Wang M, Sun $\mathrm{Y}$, Cao H. [Clinicopathological classification and prognostic factor s of gastrointestinal neuroendocrine neoplasms: an analysis of 119 cases]. [Article in Chinese]. Zhonghua Wei Chang Wai Ke Za Zhi. 2017; 20:997-1001.

8. Kim ST, Ha SY, Lee S, Ahn S, Lee J, Park SH, Park JO, Lim HY, Kang WK, Kim KM, Park YS. The Impact of PDL1 Expression in Patients with Metastatic GEP-NETs. J Cancer. 2016; 7:484-9. https://doi.org/10.7150/jca.13711.

9. Achkar T, Tarhini AA. The use of immunotherapy in the treatment of melanoma. J Hematol Oncol. 2017; 10:88. https://doi.org/10.1186/s13045-017-0458-3.

10. Parry RV, Chemnitz JM, Frauwirth KA, Lanfranco AR, Braunstein I, Kobayashi SV, Linsley PS, Thompson CB, Riley JL. CTLA-4 and PD-1 receptors inhibit T-cell activation by distinct mechanisms. Mol Cell Biol. 2005; 25:9543-53.

https://doi.org/10.1128/mcb.25.21.9543-9553.2005.

11. Shen M, Ren X. Highlights on immune checkpoint inhibitors in non-small cell lung cancer. Tumour Biol. 2017; 39:1010428317695013.

https://doi.org/10.1177/1010428317695013.

12. Schultheis AM, Scheel AH, Ozretic L, George J, Thomas RK, Hagemann T, Zander T, Wolf J, Buettner R. PD-L1 expression in small cell neuroendocrine carcinomas. Eur J
Cancer. 2015; 51:421-6.

https://doi.org/10.1016/j.ejca.2014.12.006.

13. Kaufman HL, Russell J, Hamid O, Bhatia S, Terheyden P, D'Angelo SP, Shih KC, Lebbe C, Linette GP, Milella M, Brownell I, Lewis KD, Lorch JH, et al. Avelumab in patients with chemotherapy-refractory metastatic Merkel cell carcinoma: a multicentre, single-group, open-label, phase 2 trial. Lancet Oncol. 2016; 17:1374-85. https://doi.org/10.1016/s1470-2045(16)30364-3.

14. Nghiem PT, Bhatia S, Lipson EJ, Kudchadkar RR, Miller NJ, Annamalai L, Berry S, Chartash EK, Daud A, Fling SP, Friedlander PA, Kluger HM, Kohrt HE, et al. PD-1 Blockade with Pembrolizumab in Advanced Merkel-Cell Carcinoma. N Engl J Med. 2016; 374:2542-52. https://doi.org/10.1056/NEJMoa1603702.

15. Schadendorf D, Nghiem $P$, Bhatia S, Hauschild A, Saiag P, Mahnke L, Hariharan S, Kaufman HL. Immune evasion mechanisms and immune checkpoint inhibition in advanced merkel cell carcinoma. Oncoimmunology. 2017; 6:e1338237.

https://doi.org/10.1080/2162402x.2017.1338237.

16. Barkdull S, Brownell I. PD-L1 blockade with avelumab: A new paradigm for treating Merkel cell carcinoma. Cancer Biol Ther. 2017; 18:937-9.

https://doi.org/10.1080/15384047.2017.1394552.

17. Alexandrov LB, Nik-Zainal S, Wedge DC, Aparicio SA, Behjati S, Biankin AV, Bignell GR, Bolli N, Borg A, Borresen-Dale AL, Boyault S, Burkhardt B, Butler AP, et al. Signatures of mutational processes in human cancer. Nature. 2013; 500:415-21.

https://doi.org/10.1038/nature12477.

18. Sahnane N, Furlan D, Monti M, Romualdi C, Vanoli A, Vicari E, Solcia E, Capella C, Sessa F, La Rosa S. Microsatellite unstable gastrointestinal neuroendocrine carcinomas: a new clinicopathologic entity. Endocr Relat Cancer. 2015; 22:35-45.

https://doi.org/10.1530/erc-14-0410.

19. Girardi DM, Silva ACB, Rego JFM, Coudry RA, Riechelmann RP. Unraveling molecular pathways of poorly differentiated neuroendocrine carcinomas of the gastroenteropancreatic system: A systematic review. Cancer Treat Rev. 2017; 56:28-35.

https://doi.org/10.1016/j.ctrv.2017.04.002.

20. Hannoun-Levi JM, Peiffert D. Dose rate in brachytherapy using after-loading machine: pulsed or high-dose rate? Cancer Radiother. 2014; 18:437-40.

https://doi.org/10.1016/j.canrad.2014.07.156.

21. Ordoñez Zúñiga D, Dávila Fajardo R. A review of the clinical experience in pulsed dose rate brachytherapy. Br J Radiol. 2015; 88:20150310. https://doi.org/10.1259/bjr.20150310.

22. Gilabert M, Rho YS, Kavan P. Targeted Therapies Provide Treatment Options for Poorly Differentiated Pancreatic 
Neuroendocrine Carcinomas. Oncology. 2017; 92:170-2. https://doi.org/10.1159/000452279.

23. Fonseca PJ, Uriol E, Galvan JA, Alvarez C, Perez Q, Villanueva N, Berros JP, Izquierdo M, Vieitez JM. Prolonged clinical benefit of everolimus therapy in the management of high-grade pancreatic neuroendocrine carcinoma. Case Rep Oncol. 2013; 6:441-9.

https://doi.org/10.1159/000354754.

24. Rinke A, Wiedenmann B, Auernhammer C, Bartenstein P, Bartsch DK, Begum N, Faiss S, Fottner C, Gebauer B, Goretzki P, Jansen PL, Pöpperl G, Scherübl H, et al. S2kLeitlinie Neuroendokrine Tumore. Z Gastroenterol. 2018; 56:583-681. https://doi.org/10.1055/a-0604-2924.

25. Pavel M, O'Toole D, Costa F, Capdevila J, Gross D, Kianmanesh R, Krenning E, Knigge U, Salazar R, Pape UF, Öberg K. ENETS Consensus Guidelines Update for the Management of Distant Metastatic Disease of Intestinal, Pancreatic, Bronchial Neuroendocrine Neoplasms (NEN) and NEN of Unknown Primary Site. Neuroendocrinology. 2016; 103:172-85.

26. Garon EB, Rizvi NA, Hui R, Leighl N, Balmanoukian AS, Eder JP, Patnaik A, Aggarwal C, Gubens M, Horn L, Carcereny E, Ahn MJ, Felip E, et al. Pembrolizumab for the treatment of non-small-cell lung cancer. N Engl J Med. 2015; 372:2018-28.

https://doi.org/10.1056/NEJMoa1501824.

27. Center FCC. (October 26, 2016). A Phase 2, Open-label Study of Pembrolizumab Monotherapy in Patients With Metastatic High Grade Neuroendocrine Tumors. https://clinicaltrials.gov/ct2/show/NCT02939651.

28. Utah Uo. Pembrolizumab for the Treatment of Recurrent High Grade Neuroendocrine Carcinoma. https://clinicaltrials.gov/ct2/show/NCT03190213.

29. University D. (July 1, 2017). Phase Ib/II Study of Pembrolizumab With Lanreotide Depot for Gastroenteropancreatic Neuroendocrine Tumors. https://clinicaltrials.gov/ct2/show/NCT03043664.

30. Carbognin L, Pilotto S, Milella M, Vaccaro V, Brunelli M, Calio A, Cuppone F, Sperduti I, Giannarelli D, Chilosi M, Bronte V, Scarpa A, Bria E, et al. Differential Activity of Nivolumab, Pembrolizumab and MPDL3280A according to the Tumor Expression of Programmed Death-Ligand-1 (PD-L1): Sensitivity Analysis of Trials in Melanoma, Lung and Genitourinary Cancers. PLoS One. 2015; 10:e0130142. https://doi.org/10.1371/journal.pone.0130142.

31. Mahoney KM, Freeman GJ, McDermott DF. The Next Immune-Checkpoint Inhibitors: PD-1/PD-L1 Blockade in Melanoma. Clin Ther. 2015; 37:764-82.

https://doi.org/10.1016/j.clinthera.2015.02.018.

32. Schott M, Feldkamp J, Lettmann M, Simon D, Scherbaum WA, Seissler J. Dendritic cell immunotherapy in a neuroendocrine pancreas carcinoma. Clin Endocrinol (Oxf). $2001 ; 55: 271-7$.
33. Antonia SJ, Vansteenkiste JF, Moon E. Immunotherapy: Beyond Anti-PD-1 and Anti-PD-L1 Therapies. Am Soc Clin Oncol Educ Book. 2016; 35:e450-8. https://doi.org/10.14694/edbk_158712.

34. Toulmonde M, Penel N, Adam J, Chevreau C, Blay JY, Le Cesne A, Bompas E, Piperno-Neumann S, Cousin S, Grellety T, Ryckewaert T, Bessede A, Ghiringhelli F, et al. Use of PD-1 Targeting, Macrophage Infiltration, and IDO Pathway Activation in Sarcomas: A Phase 2 Clinical Trial. JAMA Oncol. 2018; 4:93-97.

https://doi.org/10.1001/jamaoncol.2017.1617.

35. Iversen TZ. Immune modulations during chemoimmunotherapy \& novel vaccine strategies - in metastatic melanoma and non small-cell lung cancer. Dan Med J. 2013; 60:B4774.

36. Epacadostat Shows Value in Two SCCHN Trials. Cancer Discov. 2017; 7:OF2. https://doi.org/10.1158/2159-8290.cd-nb2017-100.

37. Rizvi NA, Hellmann MD, Snyder A, Kvistborg P, Makarov V, Havel JJ, Lee W, Yuan J, Wong P, Ho TS, Miller ML, Rekhtman N, Moreira AL, et al. Cancer immunology. Mutational landscape determines sensitivity to PD-1 blockade in non-small cell lung cancer. Science. 2015; 348:124-8. https://doi.org/10.1126/science.aaa1348.

38. La Rosa S, Marando A, Furlan D, Sahnane N, Capella C. Colorectal poorly differentiated neuroendocrine carcinomas and mixed adenoneuroendocrine carcinomas: insights into the diagnostic immunophenotype, assessment of methylation profile, and search for prognostic markers. Am J Surg Pathol. 2012; 36:601-11.

39. Stelow E, Moskaluk C, Mills S. The mismatch repair protein status of colorectal small cell neuroendocrine carcinomas. Am J Surg Pathol. 2006; 30:1401-4.

40. Lubensky I, Zhuang Z. Molecular genetic events in gastrointestinal and pancreatic neuroendocrine tumors. Endocr Pathol. 2007; 18:156-62.

41. Furlan D, Sahnane N, Mazzoni M, Pastorino R, Carnevali I, Stefanoli M, Ferretti A, Chiaravalli A, La Rosa S, Capella C. Diagnostic utility of MS-MLPA in DNA methylation profiling of adenocarcinomas and neuroendocrine carcinomas of the colon-rectum. Virchows Arch. 2013; 462:47-56.

42. Schmidt D, Wiedenmann B. Extremely Long Survival under Combined Immunotherapy in a Metastatic Functional Neuroendocrine Neoplasia Patient. Neuroendocrinology. 2018; 106:381-8. https://doi.org/10.1159/000486417.

43. Hamid O, Puzanov I, Dummer R, Schachter J, Daud A, Schadendorf D, Blank C, Cranmer LD, Robert C, Pavlick AC, Gonzalez R, Hodi FS, Ascierto PA, et al. Final analysis of a randomised trial comparing pembrolizumab versus investigator-choice chemotherapy for ipilimumab-refractory advanced melanoma. Eur J Cancer. 2017; 86:37-45.

https://doi.org/10.1016/j.ejca.2017.07.022. 
44. Petrella TM, Robert C, Richtig E, Miller WH Jr, Masucci GV, Walpole E, Lebbe C, Steven N, Middleton MR, Hille D, Zhou W, Ibrahim N, Cebon J. Patient-reported outcomes in KEYNOTE-006, a randomised study of pembrolizumab versus ipilimumab in patients with advanced melanoma. Eur J Cancer. 2017; 86:115-24. https://doi.org/10.1016/j.ejca.2017.08.032.

45. Wolchok JD, Chiarion-Sileni V, Gonzalez R, Rutkowski P, Grob JJ, Cowey CL, Lao CD, Wagstaff J, Schadendorf D, Ferrucci PF, Smylie M, Dummer R, Hill A, et al. Overall Survival with Combined Nivolumab and Ipilimumab in Advanced Melanoma. N Engl J Med. 2017; 377:1345-56. https://doi.org/10.1056/NEJMoa1709684.

46. Micheel A, Aigner F, Henke O. [Histologic Remission following Neoadjuvant Immunotherapy in a Patient with Lynch-Syndrome and Primarily Unresectable Relapse of Rectum Carcinoma]. [Article in German]. Dtsch Med Wochenschr. 2017; 142:842-6. https://doi.org/10.1055/s-0043-101212.

47. Hecht M, Buttner-Herold M, Erlenbach-Wunsch K, Haderlein M, Croner R, Grutzmann R, Hartmann A, Fietkau $\mathrm{R}$, Distel LV. PD-L1 is upregulated by radiochemotherapy in rectal adenocarcinoma patients and associated with a favourable prognosis. Eur J Cancer. 2016; 65:52-60. https://doi.org/10.1016/j.ejca.2016.06.015.

48. Emory University. (March 8, 2016). Tremelimumab and Durvalumab With or Without Radiation Therapy in Patients With Relapsed Small Cell Lung Cancer. https://clinicaltrials.gov/ct2/show/NCT02701400.
49. Verbrugge I, Hagekyriakou J, Sharp LL, Galli M, West A, McLaughlin NM, Duret H, Yagita H, Johnstone RW, Smyth MJ, Haynes NM. Radiotherapy increases the permissiveness of established mammary tumors to rejection by immunomodulatory antibodies. Cancer Res. 2012; 72:3163-74.

https://doi.org/10.1158/0008-5472.Can-12-0210.

50. Deng L, Liang H, Burnette B, Beckett M, Darga T, Weichselbaum RR, Fu YX. Irradiation and anti-PD-L1 treatment synergistically promote antitumor immunity in mice. J Clin Invest. 2014; 124:687-95.

https://doi.org/10.1172/jci67313.

51. Derosa L, Hellmann MD, Spaziano M, Halpenny D, Fidelle M, Rizvi H, Long N, Plodkowski AJ, Arbour KC, Chaft JE, Rouche JA, Zitvogel L, Zalcman G, et al. Negative association of antibiotics on clinical activity of immune checkpoint inhibitors in patients with advanced renal cell and non-small cell lung cancer. Ann Oncol. 2018; 29:14371444.

https://doi.org/10.1093/annonc/mdy103.

52. Zitvogel L, Ma Y, Raoult D, Kroemer G, Gajewski TF. The microbiome in cancer immunotherapy: Diagnostic tools and therapeutic strategies. Science. 2018; 359:1366-70. https://doi.org/10.1126/science.aar6918.

53. Kroemer G, Zitvogel L. Cancer immunotherapy in 2017: The breakthrough of the microbiota. Nat Rev Immunol. 2018; 18:87-8. https://doi.org/10.1038/nri.2018.4. 